\title{
The Challenge of Practicing Pediatric Rheumatology in Developing Countries (*)
}

\author{
Jorge M Lopez Benitez* \\ Director, Pediatric Rheumatology Program, La Costa Medical Center, Asuncion, Paraguay.
}

Received: June 16, 2018; Accepted: July 27, 2018; Published: August 03, 2018

*Corresponding author: Jorge M Lopez Benitez, Director, Pediatric Rheumatology Program, La Costa Medical Center, Asuncion, Paraguay. Tel: +595-0972281381,0212171769; E-mail: jmlopezbenitez@gmail.com

\section{Editorial}

SAfter practicing pediatric rheumatology for more than 10 years in Boston, coming back to Paraguay, my home country, was a challenge.

In Paraguay, we have a lot to improve in health care in general, and in rheumatology in particular.

For starters, we have other diseases to think about, mainly infectious ones and other variables to put in our "thinking cap" like the nutritional status of our patients, which have a huge impact on diagnosis and treatment [1].

Having practice in the Northeast of the US, I do have experience on some infectious process like Lyme disease. In Paraguay, although we have deers and ticks, they are not the species that transmits borrelia burdogferi. We do, however, have to think first about tuberculosis, leptospirosis, dengue, chikungunya, zika and others such as intestinal parasites. These can mimic inflammatory or autoimmune process, and some, like chikungunya, can actually trigger a chronic form of arthritis. Others can present with prolonged fever, exanthemas and arthralgias, and others with chronic diarrhea and weight loss [2].

So, our first challenge is the "easy" one to overcome; a solid clinical training in medicine or pediatrics and, of course, an outstanding one in rheumatology or pediatric rheumatology. As one of my mentors, Dr. Jane Schaller used to say..."a good pediatric rheumatologist must be a superb pediatrician first".

The next ones are the tough ones. Laboratory evaluation is hard, as we often times do not have the necessary ones to help us with the diagnosis, to rule out other process, to monitor disease activity or drugs side effects, and when we do, the family cannot afford them or they are not reliable. Imaging studies are also tough, especially in pediatrics as we do not have trained pediatric radiologists. The equipments are basic, and although we can get around, it does not make our life easier at all [3].

We are well behind in medications too, particularly in biologics. We do have a few provided by the social security system, but not all the population is within this system, and these drugs are truly unaffordable for the rest of the population.

Although I understand that as a matter of public health in countries such as Paraguay, there are other priorities, I think that we need to provide quality medical access to all the population. A new dawn is coming in Paraguay with the newly elected government and I have high hopes that there will be a revolution in public health that will benefit our patients too.

In the meantime, we will continue to provide the best care to our patients, with a solid clinical training and inventing resources as we go along. As other of my mentors, Dr Laurie Miller, used to say...."pediatric rheumatology is never boring". Well, I can vow that is even less boring within this health system [1-4].

(*) The designations "developed" and "developing" are intended for statistical convenience and do not necessarily express a judgment about the stage reached by a particular country or area in the development process.

\section{References}

1. United Nations. Standard country or Area Codes for Statistical Use. Series M, No. 49, Rev. 4. (United Nations publication, Sales No. M.98. XVII.9). Statics division.

2. Murray SA. Out of Africa: some lessons for general practice/family medicine in developed countries? Family Practice. 2000; 17(5):361363. Doi: 10.1093/fampra/17.5.361.

3. Garcia F J. Beyond special and differential treatment. Boston College Int Comp Law Rev. International Trade Law Commons. 2004; 27(2): 91-317.

4. BRIDGES Weekly Trade News Digest. 2002; 6:1-8.

Citation: Lopez Benitez JM (2018) The Challenge of Practicing Pediatric Rheumatology in Developing Countries (*). J Rheumatol Arthritic Dis 3(2): $1-4$. 